\title{
Toward a More Efficient and Innovative Electricity Sector in Russia
}

Consultation Paper 
The International Energy Agency (IEA), an autonomous agency, was established in November 1974. Its primary mandate was - and is - two-fold: to promote energy security amongst its member countries through collective response to physical disruptions in oil supply, and provide authoritative research and analysis on ways to ensure reliable, affordable and clean energy for its 28 member countries and beyond. The IEA carries out a comprehensive programme of energy co-operation among its member countries, each of which is obliged to hold oil stocks equivalent to 90 days of its net imports. The Agency's aims include the following objectives:

- Secure member countries' access to reliable and ample supplies of all forms of energy; in particular, through maintaining effective emergency response capabilities in case of oil supply disruptions.

- Promote sustainable energy policies that spur economic growth and environmental protection in a global context - particularly in terms of reducing greenhouse-gas emissions that contribute to climate change.

- Improve transparency of international markets through collection and analysis of energy data.

- Support global collaboration on energy technology to secure future energy supplies and mitigate their environmental impact, including through improved energy

efficiency and development and deployment of low-carbon technologies.

- Find solutions to global energy challenges through engagement and dialogue with non-member countries, industry, international organisations and other stakeholders.

IEA member countries:

(C) OECD/IEA, 2012

\section{International Energy Agency}

9 rue de la Fédération 75739 Paris Cedex 15, France

www.iea.org

\section{Spain}

Sweden

\section{Switzerland}

Turkey

\section{United Kingdom}

United States 


\section{Table of Contents}

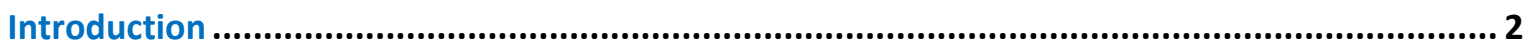

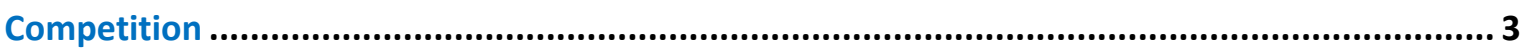

Wholesale market structure ........................................................................................... 3

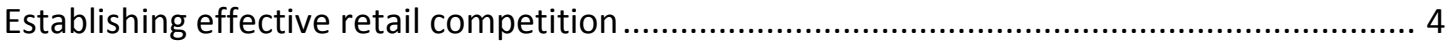

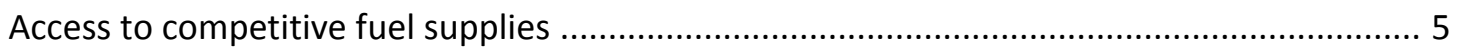

Complementary measures to promote competition ............................................................... 6

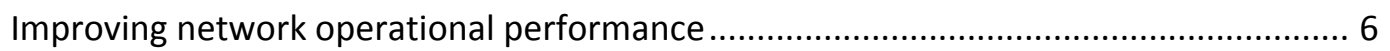

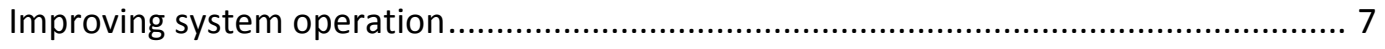

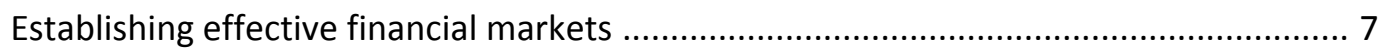

Toward more efficient combined heat and power (CHP) plant participation .................... 8

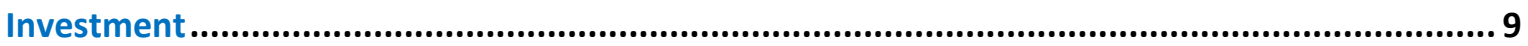

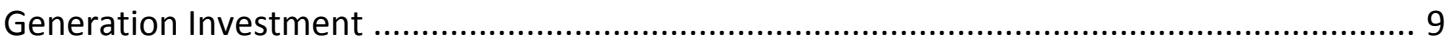

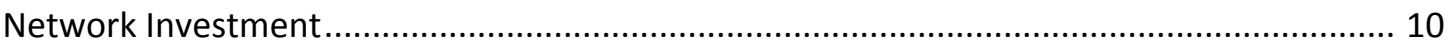

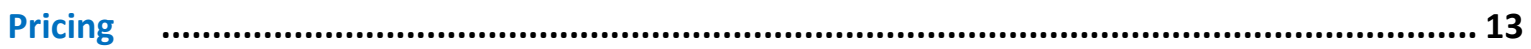

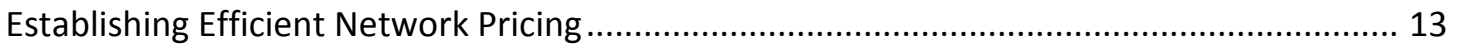

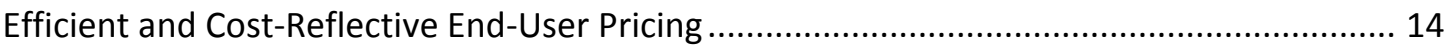

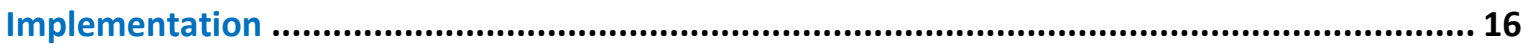

Acronyms, abbreviations and units of measure ….................................................................. 17

\section{List of Boxes}

Box 1 Discussion Points on the Wholesale Market Structure ...................................................... 4

Box 2 Discussion Points on Establishing Effective Retail Market Competition ................................. 5

Box 3 Discussion Points on Access to Competitive Fuel Supplies ................................................. 6

Box 4 Discussion Points on Complementary Measures to Promote Competition........................... 8

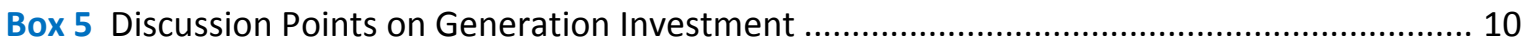

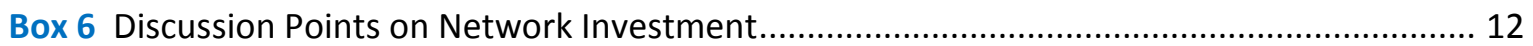

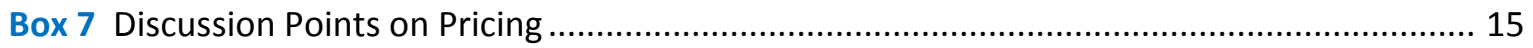

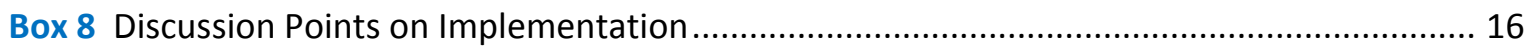




\section{Introduction}

Russia is in the process of one of the most ambitious electricity sector reforms ever undertaken, reflecting the importance of an efficient and reliable electricity sector for promoting economic activity, growth and community prosperity. The outcome of this process will have a substantial

Page 12 impact on Russia's energy sector and longer-term economic performance. It will help to determine the nature and pace of investment and modernisation of the sector and will help to shape incentives for efficient, flexible and innovative operation and end-use.

In 2005, the IEA published a study on Russian electricity reform which documented the reform package and highlighted some potential implementation challenges [Russian Electricity Reform: Emerging Challenges and Opportunities ${ }^{1}$. Reform achievements since the initial IEA study have been impressive, including:

- unbundling and substantial privatisation of generation infrastructure;

- introduction of an investment mechanism including an investment obligation targeted at new build as well as a system of capacity payments for existing generation;

- implementation of a wholesale spot market covering European Russia, the Urals and Siberia;

- economic regulation and open access arrangements for transmission and distribution networks;

- progress toward more cost-reflective pricing; and

- establishment and strengthening of key market and regulatory institutions.

However, the outcome remains uncertain at this stage. Electricity reform is entering a critical phase in Russia. Hence, the IEA considers this an appropriate time to update its original work. The new study will outline trends and progress since 2005, and will examine the key remaining challenges drawing on the experience of IEA member countries to inform the analysis as appropriate. It is being undertaken in consultation with key Russian stakeholders including government officials, regulators, the wholesale market operator, the system operator, industry participants, major users, finance and industry analysts, academic and research institutions, to ensure the analysis reflects a sound, evidence-based understanding of the key issues.

This paper outlines some key issues and preliminary views emerging from IEA analysis and consultations to date, and is provided to facilitate more effective consultation and dialogue with key stakeholders.

The IEA would welcome comments on the issues and questions raised in this document, or any other observations stakeholders may wish to raise that may be of relevance to this study.

Please forward any written comments in English or Russian to RERS@iea.org. Comments would be gratefully received before close of business, Monday 30 April 2012.

Any other questions in relation to this project should be directed to Douglas Cooke, Project Leader (doug.cooke@iea.org) or Isabel Murray, Russia Programme Manager (isabel.murray@iea.org).

\footnotetext{
${ }^{1}$ See: http://www.iea.org/textbase/nppdf/free/archives/russianelec.pdf
} 


\section{Competition}

Introduction of effective competition in the contestable parts of the electricity supply chain is a critical pre-condition for delivering efficient, innovative and responsive market-based outcomes that maximise economic benefits and dividends for consumers. Russian electricity reform policies seek to establish effective competition as a foundation for delivering these outcomes.

\section{Wholesale market structure}

IEA experience indicates that the strength and dynamism of competition in wholesale electricity markets is greatly affected by the market structure, with a less concentrated market structure more likely to deliver efficient and innovative outcomes.

Our preliminary analysis of Russia's wholesale market structure ${ }^{2}$ suggests relatively diversified ownership consistent with a competitive market structure on a national basis. However, experience to date shows that network congestion can lead to fragmentation of the national market into smaller regional markets, especially during peak periods or at other times when the power system is under stress. Our analysis, using the five wholesale trading hubs as a proxy for the potential impact of congestion on market structure, suggests that congestion could significantly increase effective concentration in all regions, with some regions recording levels of concentration consistent with the presence of significant market power.

Ultimately, a competitive wholesale market structure is best achieved through diversity of ownership. Although the 2008 privatisation brought several new entrants and greater diversity of generation ownership, several stakeholders noted that government-owned enterprises own or control over $60 \%$ of total generation assets and that a trend toward consolidation of ownership within government-owned entities is beginning to emerge. Consolidation into government ownership after unbundling and privatisation is an unusual development based on IEA experience and may have implications for competitive neutrality and efficient market operation and development in the longer term.

Government ownership is not a problem of itself, so long as government-owned enterprises are operated on an arm's-length basis subject to normal corporate governance requirements and commercial practices. Several stakeholders suggested that scope may exist to improve the operational and investment performance of government-owned enterprises. IEA experience suggests that increasing the level and diversity of private ownership can result in substantial efficiency improvements.

Considerable scope exists for the Government to improve diversity of ownership and wholesale competition through further divestment, or through other initiatives such as virtual power plants or other mechanisms to sell rights to the output of publicly owned generators. Virtual power plants may provide a practical option for assets that may prove difficult to privatise for wider public policy reasons, like nuclear and some hydro facilities.

IEA electricity markets have generally experienced considerable rationalisation post reform, involving horizontal and vertical re-integration both within the electricity value chain and into upstream fuel supply chains. Complex ownership structures have emerged including considerable cross-ownership and the creation of mixed technology portfolios that have the potential to weaken transparency and dilute competition and efficient market development. Effective

\footnotetext{
${ }^{2}$ Our preliminary analysis employed the Herfindahl-Hirschman Index to assess concentration and a residual supply index to examine the scope for exercising market power in practice.
} 
competition regulation has a crucial role to play in maintaining a competitive wholesale market structure and efficient outcomes. The Federal Antimonopoly Service (FAS) has performed well to date and is generally well respected among market participants. It will need to provide objective and consistent supervision to ensure a competitive market structure is maintained over time.

What potential exists for further privatisation of generation assets or sale of generation output rights? How else could diversity of ownership be improved?

How effective is competition supervision? How could it be improved?

\section{Establishing effective retail competition}

Dynamic and competitive retail markets are needed to drive efficiency dividends through the value chain to end users in the form of more efficient prices and more innovative services. They are an important pre-condition for developing effective customer choice and demand-side flexibility, which can enhance efficient price formation, introduce greater competitive discipline and help moderate the potential for market power abuse.

Russian policymakers have recognised the importance of developing a competitive retail sector. Large-scale industrial and commercial users are currently contestable. At present, the Government plans to remove remaining cross-subsidies for regulated small volume customers from 2014, which could open the way for the introduction of full retail contestability.

Several stakeholders noted the importance of establishing well-functioning retail markets and the need to improve retail competition. Some noted that little progress had been made on developing the legal and regulatory framework necessary to support effective retail competition and customer choice. Concerns were also raised about the market structure with some suggesting that reform of incumbent Guaranteeing Suppliers would be necessary to deliver a more competitive retail market structure.

IEA experience suggests that the introduction of retail competition and customer choice raises a range of complex and sensitive public policy issues, especially in the context of extending competition to residential consumers. An integrated policy approach is required to address the many details including:

- introduction of cost-reflective pricing;

- establishing an effective legal and regulatory framework;

- establishing a competitive retail market structure;

- establishing the administrative and commercial processes to support choice including contracting, switching and billing procedures;

- providing access to information needed to support competition and innovative product development while protecting privacy;

- educating consumers so they can exercise choice effectively; and

- establishing effective competition regulation to supervise retail markets and protect consumers.

We understand the government is finalising a new decree that will establish the policy and regulatory framework for addressing many of these issues. It is scheduled for publication in March 2012. 
Leading IEA jurisdictions are also in the process of introducing enabling technologies that provide cost-effective real-time metering information, verification and control capability to support the development of innovative products that deliver greater demand-side flexibility and more effective customer choice.

Extending retail competition to smaller volume customers has proven to be a major and timeconsuming undertaking in IEA countries. Implementation needs to be done in a way that engages key stakeholders and consumers, to build their confidence, capability and willingness to become active market participants.

In practice, some IEA countries have found that the potential benefits of extending choice to the smallest customers may be outweighed by the associated costs. It is important for the wider credibility of the reform program that competition is introduced where it is likely to deliver tangible benefits to consumers. Some IEA countries have undertaken benefit-cost assessments to inform policymakers about the merits of extending full retail contestability to particular customer classes and regions. Russian policymakers may wish to consider a similar approach.

Where the development of effective retail competition is unlikely to emerge in the short-term there may be opportunities to improve regulation and introduce more market-based arrangements to help improve pass through of efficiency benefits to end-users. Consideration could be given to improving the regulatory incentives on Guaranteeing Suppliers to deliver more cost-effective services. Structural reform might also be considered to complement regulatory incentives. One interim market-based option might be to establish a series of larger-scale supply franchises and to open them for competitive tender. These franchises could ultimately form the basis for establishing a smaller number of competitive regional supply companies that could provide the foundation for a competitive and commercially viable national retail market structure that could ultimately support the introduction of full customer choice.

\section{Box 2 • Discussion Points on Establishing Effective Retail Market Competition}

How could market structure, market-based mechanisms and regulatory arrangements be improved to deliver more cost-effective and competitive retail market outcomes?

What are the other key challenges and priorities for developing effective retail competition? How should they be addressed?

\section{Access to competitive fuel supplies}

Fuel costs are a key determinant of short-run marginal costs for thermal generators, which generally set system marginal prices on the Russian wholesale spot market. Gas supplies are of particular importance given that gas-fired generators represent over $60 \%$ of thermal generation capacity and around $40 \%$ of domestic electricity production. Access to competitively priced fuel on fair terms and conditions is a key pre-requisite for minimising wholesale electricity prices.

Several stakeholders raised concerns about the competitiveness of upstream fuel supply markets for thermal generators, noting that a lack of effective competition was reflected in higher prices and less flexibility than might otherwise be expected in a more transparent and contestable marketplace.

Several raised particular concerns about natural gas supply markets, especially the inability of potential new entrants to access the domestic pipeline system on fair and reasonable terms. Some claimed this restriction represented an insurmountable barrier to the development of greater diversity of supply and competition in key domestic gas markets. 
Gazprom dominates the domestic gas market with around $75 \%$ market share. However, independent producers are emerging, such as Novatek, which is beginning to build its presence in the thermal generation fuel supply market. Gazprom also holds substantial electricity generation interests, which raises concerns about the potential for Gazprom to discriminate against competing thermal generators, either by denying them access to sufficient competitively-priced gas, or by favoring its electricity generating subsidiaries.

Stakeholders suggested that key steps toward addressing these concerns include:

- strengthening third party access arrangements, possibly including the introduction of regulated reference tariff services to support more informed and effective negotiations;

- improving transparency and access to spare pipeline capacity for third parties; and

- re-establishing a wholesale gas trading exchange to encourage greater flexibility and transparency.

\section{Box $3 \bullet$ Discussion Points on Access to Competitive Fuel Supplies}

How could market-based mechanisms and regulatory arrangements be improved to deliver more efficient and competitive outcomes?

What are the other key challenges and priorities for strengthening access to competitive fuel supplies? How could they be addressed?

\section{Complementary measures to promote competition}

Several other factors have the potential to help improve competition either by strengthening fundamental market structure or by helping to improve incentives for more efficient and competitive commercial behaviour.

\section{Improving network operational performance}

More efficient operation of transmission and distribution networks can help to alleviate congestion, promote efficient trade and strengthen integration of markets, leading to more competitive and efficient outcomes in the contestable parts of the value chain. Economic regulation tends to focus on reducing operating costs. Benchmarking mechanisms, sometimes complemented with efficiency sharing arrangements, are used in many IEA countries to create incentives for operational cost efficiencies, especially in the distribution sector. However, most regulatory regimes tend to focus on reducing costs at the expense of service delivery.

IEA experience suggests that considerable scope exists to improve regulatory incentives for more market-responsive network operation. Several IEA regulators have introduced innovative schemes that link a portion of the regulated return to the market impact of operational decisions affecting network capability and congestion. Russian regulators could consider the merits of employing similar approaches to strengthen incentives to maximise network capability when it is of greatest value to the market.

Stakeholders have raised concerns about network management, particularly of distribution businesses, suggesting that inefficient management is leading to a fundamental lack of operational responsiveness to incentive-based regulation, which could substantially reduce the effectiveness of economic regulation and result in higher operating costs and lower service quality than might be expected. Russian policymakers are responding to this concern by exploring options for increasing private sector management of network businesses. This is a positive 
development. IEA experience suggests that private sector network management can deliver significant operational efficiencies in response to effective regulatory supervision and incentives. Regulators in some IEA countries have also introduced annual performance reporting requirements to provide greater transparency and to aid regulatory scrutiny of operational performance.

\section{Improving system operation}

Transparent and objective system operation is needed to deliver efficient dispatch and network operation that supports competitive and efficient wholesale market outcomes.

Some stakeholders raised concerns about certain aspects of system operation. It was suggested that the system operator's focus on reliability combined with a relatively unsophisticated system model and dispatch engine were resulting in an unduly conservative dispatch and power flow regulation that could increase effective network congestion, reducing the potential for interregional trade and competition. It was also suggested that an unduly conservative approach to contingency reserve management may be resulting in tighter supply-demand balances, and higher prices, in some regions than is warranted.

IEA experience suggests that more market-based procurement of contingency reserves and other ancillary services can lead to a significant reduction in these costs without diminishing effectiveness. Policymakers and regulators may want to consider ways to introduce marketbased contingency reserves procurement to help reduce costs and improve market efficiency. Consideration could also be given to improving the system operator's situational awareness, by upgrading its system model and dispatch capability, to increase its capacity to maximise real-time power system performance at least cost.

\section{Establishing effective financial markets}

Wholesale electricity markets are inherently volatile, reflecting the unique characteristics of electricity ${ }^{3}$. IEA experience indicates that efficient financial markets facilitate cost-effective risk management, resulting in:

- more efficient price formation;

- a more competitive market structure;

- reduced incentives for strategic behaviour;

- stronger signals for more efficiently timed and sized investment; and

- reduced need for regulatory intervention to manage price volatility.

IEA experience suggests that financial markets can be slow to develop, with bilateral over-thecounter trading generally developing initially and exchange traded volumes growing as markets mature. Russian experience to date appears similar. Day-ahead physical spot market transactions appear to dominate wholesale markets with little information available on the nature and volume of financial trading. Trading volumes on the Moscow Energy Exchange represent only a small fraction of overall physical volumes. One stakeholder noted that legislation governing the nature and trading of financial products does not adequately define hedging instruments and that this creates risk that discourages participation in the financial market.

\footnotetext{
${ }^{3}$ In particular, electricity generally cannot be cost-effectively stored and electricity needs to be balanced in real-time. These attributes combined with relatively inelastic demand responses in real-time and hard capacity constraints can deliver very volatile wholesale spot prices, especially when the supply-demand balance is tight.
} 
Current global financial difficulties highlight the need for efficient financial markets that costeffectively manage risk and promote certainty for investors. Such markets can increase costeffective access to capital, which is critical for securing efficiently timed and sized investment in the longer term, especially if a move toward more efficient, market-based investment built on independent decentralised decision-making is contemplated longer-term. Russian policymakers may want to give greater priority to the development of electricity-related financial markets, drawing from the lessons of successful European exchanges, including identifying and removing any undue legal or regulatory barriers to their development and use.

\section{Toward more efficient combined heat and power (CHP) plant participation}

CHP plants are a key resource in the Russian electricity system, representing around one-third of total generating capacity. They also provide an essential district heating service, which affects their participation in wholesale electricity during the winter months ${ }^{4}$.

Heating revenues are regulated. Some stakeholders noted that regulated returns are insufficient to cover costs for most CHP plants and that this affects decisions around generating electricity, which in turn affects the efficient operation of wholesale electricity markets. It was suggested that cost-reflective, long-term heating tariffs are required to promote efficient participation in the wholesale electricity market. A heating law is in place, but the related rules and regulations to operationalise the law are yet to be developed.

New regulations affecting the heat sector will need to take account of the incentives it creates for CHP participation in electricity markets. Where possible, the new regulatory arrangements should seek to minimise the potential for distorting incentives that may lead to perverse outcomes in both sectors.

\section{Box 4 - Discussion Points on Complementary Measures to Promote Competition}

What are the main challenges to improving network operational performance? How can they be addressed?

What impact does system operation have on competitive market outcomes? How can system operation be improved?

What are the main challenges for developing effective financial markets? How should they be addressed?

What needs to be done to strengthen incentives for more efficient and dynamic CHP participation in the wholesale electricity market?

\footnotetext{
${ }^{4}$ CHP plants are added to the priority dispatch list during the winter period. Any electricity they produce receives the system marginal price from the wholesale spot market.
} 


\section{Investment}

Russia faces substantial electricity sector investment requirements over the next two decades. According to the 2011 World Energy Outlook ${ }^{5}$, Russia will require investments totalling USD 615 billion (in year-2010 dollars) in the power sector between 2011 and 2035, with more than USD 250 billion (40\%) directed to transmission and distribution and USD 360 billion directed to generation. Investment projections are largely driven by the need to refurbish and replace ageing infrastructure. Efficient electricity markets, and effective network planning and regulation will be required to deliver timely and least cost investment.

\section{Generation investment}

Attracting efficient and timely private generation investment is a key goal of the electricity reform program. New investment requirements are currently secured to 2018 through a contractual obligation placed on purchasing parties under the privatisation process (the DPM mechanism), while returns on capital for existing plant are delivered through a largely regulated capacity mechanism. This administrative approach was adopted during the transition while pricing reforms, market rules, and regulatory arrangements were being developed and bedded down, to ensure timely investment and to provide sufficient returns to avert premature closure of some capacity, particularly CHP plants. IEA experience suggests that measures of this kind may be needed during the transitional period, especially where reform is introduced in the presence of tight supply-demand balances as was the case in some Russian regions.

However, stakeholders have raised a range of concerns with this approach. According to various stakeholders, it has proven to be expensive, lacks flexibility and can restrict large customer choice, over-rewards inefficient and expensive 'must have' plants while under-rewarding some existing plant, and potentially reduces the scope for competitive new entry and incentives for innovation. It essentially introduces a form of central planning that is ultimately incompatible with delivering the policy goal of developing efficient, innovative and dynamic electricity markets reflecting the commercial choices of many individual buyers and sellers. IEA experience raises a range of other concerns with capacity mechanisms including the potential to distort and crowd out efficient investment responses, encouraging over-investment and increasing opportunities for market manipulation.

The Government is now reviewing these arrangements and examining options for securing investment beyond 2018, with the intention of moving to a more market-based approach that will deliver efficiently timed, sized and well located generation investment at least cost. Achieving this outcome will involve moving from the current centrally planned and closely regulated approach towards more liberalised arrangements where generation investments are undertaken by independent decentralised decision-makers in response to incentives created by costreflective and competitively determined prices.

IEA experience suggests that a well-functioning energy-only market provides an effective means of delivering the efficiently timed, sized and well located generation investment needed to develop a competitive, dynamic and innovative electricity sector at least cost. For instance, the Australian National Electricity Market has delivered efficiently timed, sized and well-located generation investment for the last decade using an energy-only wholesale market model.

\footnotetext{
${ }^{5}$ Figures are drawn from the New Policies Scenario of the IEA World Energy Outlook 2011.
} 
However, there are some key pre-conditions that need to be met for energy-only markets to deliver the desired outcome. Prices need to be cost-reflective through the value chain to create strong incentives for efficient investment, operation and end-use. Administrative wholesale price caps need to be high enough to allow efficient price formation and return on investment, to provide strong investment signals and to address the 'missing money' problem that has discouraged efficiently timed and sized generation investment in several IEA markets. A liquid, deep, transparent and efficient financial market is needed to support efficient risk management and to help increase access to capital at least cost. Efficient investment responses need to be informed by accurate and timely information and credible medium-term demand projections that facilitate greater market transparency. In the absence of these pre-conditions there may be need to maintain some form of capacity mechanism.

Although work is progressing to address many of these issues, our discussions to date suggest that some may not be effectively resolved by 2018. If this is the case then transitional arrangements may need to be extended beyond 2018, with the objective of introducing fully competitive arrangements once the key transitional issues have been resolved.

In the interim, there appear to be opportunities to refine existing arrangements. More transparent and competitive capacity procurement would be welcomed, perhaps drawing on the more successful models emerging among IEA members in the North-Eastern United States, Continental European or Nordic markets. We understand that a more competitive procurement mechanism is scheduled to be introduced from 2012. Options may exist to gradually replace the transitional capacity mechanism with an energy-only model for mainstream generation investment and a capacity mechanism for procuring operational reserves. Operational reserves have public good characteristics and therefore may require additional financial inducements to elicit an appropriate investment response.

\section{Box 5 - Discussion Points on Generation Investment}

How could the current DPM and capacity mechanism be improved to deliver more efficient and least cost outcomes?

Should an energy-only market model based on independent decentralised decision-making be adopted beyond the transition period? If so, how could the transition to an energy-only model be managed? What role should a capacity mechanism play in the market design beyond the transition?

What are the other main barriers for efficiently timed, sized and well-located generation investment? How could these barriers be addressed?

\section{Network investment}

There has been little investment in networks, especially distribution networks, over the last two to three decades in Russia. Aging network infrastructure is beginning to deliver deteriorating network performance including above average network losses, reduced transfer capability and increasing service disruptions. Timely and efficient network investment will be needed to strengthen and improve transmission and distribution network performance to support the development of well-functioning electricity markets.

Policymakers have recognised this challenge and introduced a form of economic regulation Regulated Asset Base (RAB) regulation - to strengthen operational and investment incentives to improve network performance at least cost. The Federal Grid Company's transmission assets were transferred to RAB regulation in 2010. RAB regulation was extended to high voltage 
regional distribution systems in 2011 , and is planned to be rolled-out to lower voltage local distribution networks over the next few years.

Timely network investment to reduce key points of inter-regional and intra-regional congestion will be critical for improving market integration and promoting more efficient trade and market development. Some stakeholders noted that the Federal Grid Company's current investment program includes projects that will help to reduce congestion affecting wholesale market performance. However, others noted that reliability rather than market integration tends to drive network investment. Policymakers and regulators could consider giving greater priority to investments that promote more effective market integration and efficient trade.

Stakeholder comments suggested that regulatory frameworks for investment planning, assessment and delivery are unclear and possibly incomplete. IEA experience suggests several ways in which the regulatory regime might be strengthened to support more efficient and timely network investment and performance.

The regulated investment framework could be strengthened by adding an economic assessment test for all new network investment and large-scale augmentations. The test could be applied to each individual project above a certain capital expenditure threshold. Individual projects would be required to demonstrate a positive net present value before they could be counted against the capital expenditure limits established at the commencement of the regulatory period and subsequently added to the regulated asset base. A mechanism of this kind has the potential to add rigour and accountability to the regulated investment process by ensuring that funding permitted under the approved capital expenditure allowance for each regulatory period is applied to projects that deliver clear economic or reliability benefits. It would provide a more flexible, objective and transparent means of managing augmentation of the regulated asset base and growth in related costs.

More effective network investment could be supported by applying more integrated and holistic investment planning and approval processes that seek to identify key projects, or groups of projects, that have the potential to deliver superior economic or reliability outcomes for the power system as a whole. Whole-of-system planning arrangements, informed and supported by independent medium-term and long-term planning information, modelling and evaluation processes, have been implemented to varying degrees in the North American, Continental European, Australian, Nordic and United Kingdom power systems. IEA experience suggests that participation of key stakeholders, especially the system and market operator, can help to address information asymmetries and investment coordination problems resulting from unbundling. Implementation would be a particular challenge at the local distribution level where planning is substantially affected by regional economic development policies which introduce various uncertainties.

Regulatory uncertainty can create risk for regulated network business that leads to undue delay or deferral of potentially efficient network investments. Regulators can take steps to help reduce this uncertainty by improving transparency around investment assessment and approval processes. Regulators in some IEA countries publish guidelines explaining how they interpret and apply rules governing regulated investments, including advice regarding information and investment assessment requirements, to help reduce compliance costs, and promote timely and efficient investment.

Smart grid and smart metering technologies have the potential to greatly improve network and wider power system performance, improving economic efficiency, customer choice and power system security. Regulatory frameworks that focus largely on cost reduction have created a barrier to the efficient and timely development and roll-out of these technologies in some IEA countries, necessitating changes to laws and rules affecting economic regulation in some cases. 
Russian policymakers and regulators could consider reviewing the legal and regulatory framework governing network investment to identify and address any potential barriers to the efficient and timely deployment of these technologies in the future.

\section{Box 6 • Discussion Points on Network Investment}

How could the RAB framework be improved to deliver more efficient and timely network investment at least cost? Is an economic test or similar mechanism needed to help improve the efficiency and accountability of network investment?

How could network planning and approval processes be strengthened to facilitate more effective and timely network investment?

What are the other key challenges affecting network investment? How could they be addressed? 


\section{Pricing}

Cost-reflective prices through the value chain are essential for delivering strong incentives for efficient investment, operation and end-use in reformed electricity systems. Establishing costreflective pricing in the Russian electricity sector has raised several substantial challenges, especially around the formation of efficient and least cost network and end-user prices.

\section{Establishing efficient network pricing}

Network charges represent around $50 \%$ to $60 \%$ of delivered electricity costs for small volume consumers, with around $80 \%$ of those charges associated with distribution network services. Recent substantial increases in end-user electricity prices have largely been driven by a rapid acceleration in network charges, particularly distribution charges.

Several stakeholders suggested that higher than expected increases in network charges reflected inexperience with the application of economic regulation. There are several legitimate drivers for increasing network charges including the need to fund efficient maintenance and new investment, and the need to lift rates of return to competitive levels that cover costs and attract capital. These drivers were not in dispute. However, concerns were raised about weaknesses in the regulatory framework that may permit inefficient investments and operating costs to be passed through to end users. Some suggested that more effective scrutiny and accountability needs to be introduced to ensure more efficient, least cost network charges in the future. Concerns were also raised about the pace of tariff adjustment. Some suggested that network charges had been permitted to increase too quickly, raising inflationary pressures and pressure for government intervention. Recent policy initiatives including tariff smoothing and extension of regulatory periods may go some way toward addressing these concerns.

Stakeholders suggested that growing network charges have been magnified by several other factors including: strategic behaviour among local distribution companies seeking to inflate their asset base prior to the application of RAB regulation; limited cost-reductions in response to incentive-based regulation among distribution businesses; and unduly conservative system operation. Together these factors have added to costs and weakened performance. Policy initiatives to test the potential to improve responsiveness through private sector management of distribution businesses are a welcome development, and if successful may open the way for greater private participation and possible ownership of distribution business in the future.

Implementation of economic regulation is a complex and demanding exercise. IEA experience indicates that all regulators go through a steep learning curve initially. Inherent information asymmetry tends to magnify the challenge. Adjustments are often required to calibrate regulatory arrangements in light of operational experience. However, as one stakeholder noted, community patience is wearing thin and further 'teething problems' of this kind may encourage policymakers to adopt simpler and more expedient solutions that might unduly compromise key reform principles and efficient outcomes. Efficient and effective roll-out will strengthen the credibility of the regulatory regime, and help build wider stakeholder, community and ultimately policy commitment to reform.

Adjustments need to be made quickly and effectively to ensure that the roll-out to local distribution businesses can proceed in a timely and effective manner that delivers efficient pricing incentives and outcomes. We understand that a new law has been proposed to refine the tariff setting procedures. Although a welcome development, it is unlikely that new rules will be established quickly enough to respond to the current situation. Interim adjustments will be needed to avoid unduly delaying RAB roll-out. 
This challenge is likely to be further magnified at the regional level by insufficient resourcing and a lack of experience and expertise with economic regulation among regional regulators. Priority will need to be given to transferring learning to date to regional regulators to help avoid these problems. Some stakeholders raised concerns about the capability of regional regulators to effectively implement RAB regulation. More transparent regulatory processes that incorporate public consultation have been used by IEA regulators to help address information asymmetry and to improve the quality of regulatory outcomes. Perhaps there may be scope to employ some form of 'peer review' or targeted consultation to help address these concerns, or to develop an association to facilitate learning and information exchange within the regulatory community. Consideration could be given to more formalised training and development programs to help build and maintain competence over time, supported by effective staff retention policies.

\section{Efficient and cost-reflective end-user pricing}

Substantial progress has been made to improve the cost-reflectivity of end-user prices, with prices for most customer classes increasing three to four fold over the last decade from a very low base. Most larger-volume users currently face delivered prices that reflect underlying costs. However, a considerable challenge remains to increase prices for the remaining regulated customer classes to cost-reflective levels. We understand that the Government is currently planning to remove all remaining cross-subsidies from electricity pricing by 2014 .

Cross-subsidies from contestable to regulated customers are estimated at around RUB 200 billion per annum at present, representing around $10 \%$ of total electricity sector revenue. The majority of the subsidy goes to regulated residential consumers and is largely delivered through concessional low-voltage distribution charges. Subsidies are also delivered through discounted regulated wholesale tariffs.

Although the absolute level of cross-subsidy is moderate, the mechanism for delivering it has resulted in a highly concentrated wealth transfer with small and medium-sized commercial customers bearing much of the burden through substantial hikes in their low-voltage distribution charges. Some evidence is emerging of medium-sized businesses choosing to invest in distributed generation rather than continuing to pay highly inflated distribution charges.

At the same time, the concentration of the subsidy among regulated residential consumers, who represent a relatively small portion of total electricity consumption, serves to increase the effective level of subsidy per unit, increasing the magnitude of the tariff rebalancing challenging. A comparison of current average regulated residential prices with a rough cost-reflective price estimate $^{6}$ suggests that residential prices may need to nearly double to reach cost-reflective levels. Despite the subsidy, evidence is emerging of growing payment defaults, suggesting that there may be little scope for further rapid and substantial tariff rebalancing at this time.

Unwinding the remaining cross-subsidies and moving to cost-reflective pricing will be a challenging but necessary task if the full benefits of electricity reform are to be realised. Public sensitivity and limited capacity among some users to absorb further tariff increases is likely to effectively limit the pace of tariff rebalancing. A coherent, consistent and well managed implementation strategy will be required to successfully complete the rebalancing. An effective approach may include the following elements:

\footnotetext{
${ }^{6}$ The estimate compares current average regulated end-user tariffs to a rough benchmark of cost-reflectivity which is the product of current average large-volume industrial and commercial tariffs covering cost-reflective wholesale and high voltage network charges and a premium added to cover efficient low-voltage distribution and retail charges.
} 
- adopting a measured approach to regulated end-user tariff rebalancing that aligns increases in end-use prices to increases in incremental capacity to pay, such as limiting increases to a fixed proportion of real growth in household income;

- developing instruments to more effectively target and directly deliver subsidy assistance, as a community service obligation (CSO), to help reduce the volume of subsidies and improve their effectiveness;

- progressively moving subsidy funding from electricity consumers to the tax payer, consistent with its treatment as a CSO.

- As a first step, quarantine cross-subsidies to the regulated components of the value chain, so that existing distortions to competitive price formation can be removed and competitive benefits maximised and passed through to end-users.

- Once quarantined, gradually increase budget funding of cross-subsidies, initially paid directly to distribution businesses, but ultimately paid directly to consumers through the CSO instrument.

- Reduce small and medium-sized commercial consumer tariffs in proportion with the decrease in their share of the subsidy funding requirement; and

- At the same time, progress implementation of the electricity reform program, especially initiatives that can deliver more cost-effective network and retail services, to help drive further cost efficiencies which may result in a gradual reduction in real cost-reflective prices over time, helping to reduce the effective subsidy per unit required.

An integrated strategy including these key elements would help minimise the period required to complete the rebalancing by combining elements that simultaneously seek to reduce costs and increase real payments in line with capacity to pay. It would also provide a mechanism that could more effectively target payments to those in greatest need, both during the transition and beyond for poorer households that may need ongoing assistance, while minimising the overall cost to the taxpayer. Importantly, it would help to create a more sustainable commercial foundation for the electricity sector into the future.

\section{Box $7 \bullet$ Discussion Points on Pricing}

What refinements need to be made to the RAB framework to help deliver more costeffective network pricing outcomes? What lessons can be drawn from experience to date to help deliver more cost-effective outcomes through the roll-out of RAB to local distribution networks?

What are the key challenges associated with unwinding remaining cross subsidies and moving toward fully cost-reflective end-user prices? How could they be addressed?

What are the other key determinants and challenges for delivering more efficient and costeffective pricing outcomes? How could they be addressed? 


\section{Implementation}

Considerable progress has been made with implementing the reform program. Achievements in recent years have been very impressive by global standards. However, an efficient and effective outcome is not guaranteed at this stage. Implementation is entering a critical phase where IEA

Page I 16 experience suggests that political will and community support is often tested and undue compromises are sometimes made.

Pressure is building as pricing reforms begin to bite and the government comes under increasing pressure to intervene in ways that could jeopardise efficient and innovative investment, operation and end-use in the longer-term, with implications for energy security, competitiveness, innovation and sustainability. The recent decision to cap end-user prices, though largely undertaken to address strategic behaviour, reinforces a perception that the government is willing to intervene and may result in the government coming under increasing pressure to unduly intervene in the future.

Implementation of such a complex reform program raises inter-related policy, regulatory and market development challenges requiring strong government leadership, reflected in consistent and holistic policy responses and an integrated implementation strategy that builds credibility and confidence in the reform program among key stakeholders.

Several stakeholders noted that no single institution has strategic responsibility for overseeing reform implementation. It was suggested that the fractured distribution of roles and responsibilities was resulting in narrow and limited responses, especially to wider cross-cutting implementation issues that demanded more strategic and holistic approaches. Others noted that frequent changes and revisions to laws, rules and market arrangements had the potential to magnify uncertainty and regulatory risk which could slow efficient and effective market development and implementation. Strengthening of coordination, possibly through a single institution or body with strategic responsibility for the delivery of the whole implementation program, may help to accelerate progress and improve implementation outcomes.

\section{Box $8 \bullet$ Discussion Points on Implementation}

How could strategic management and coordination of the implementation process be strengthened?

What are the other key remaining implementation challenges? How could they be addressed? 


\section{Acronyms, abbreviations and units of measure}

\section{Acronyms and abbreviations}

CHP

CSO

DPM

FAS

RAB

RUB

USD
Combined heat and power

Community service obligation

"Dogovor o Predostavleny Moshnosty" is a new Russian investment requirement currently secured to 2018 through a contractual obligation placed on purchasing parties under the Russian electricity privatisation process

Federal Antimonopoly Service

Regulated asset base

Roubles

United States Dollars 


\section{iea}

\section{International Energy Agency}
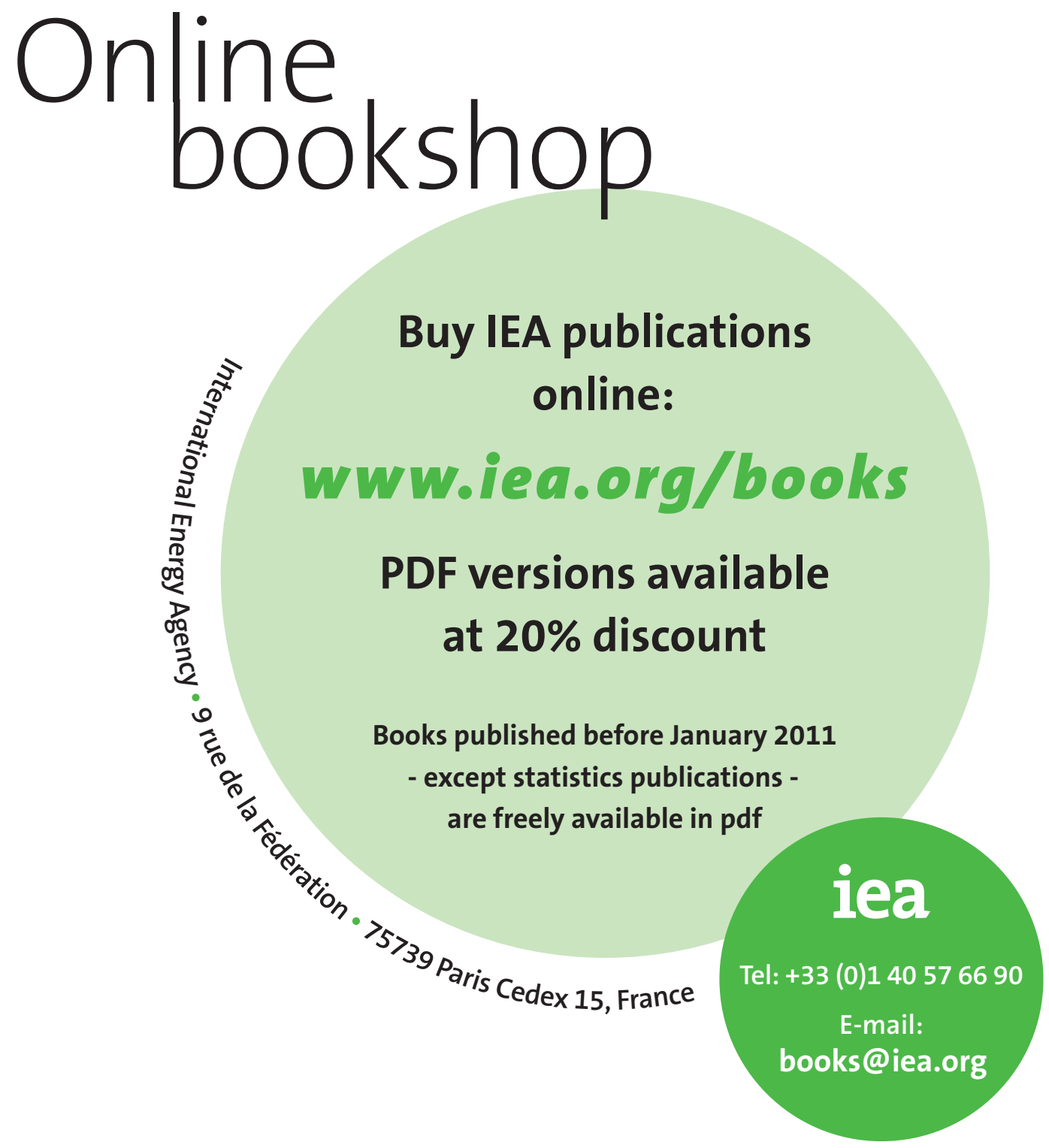